\title{
Creeping Proteins in Microporous Structures: Polymer Brush-Assisted Fabrication of 3D Gradients for Tissue Engineering
}

Citation for published version (APA):

Gunnewiek, M. K., Di Luca, A., Bollemaat, H. Z., van Blitterswijk, C. A., Vancso, G. J., Moroni, L., \& Benetti, E. M. (2015). Creeping Proteins in Microporous Structures: Polymer Brush-Assisted Fabrication of 3D Gradients for Tissue Engineering. Advanced Healthcare Materials, 4(8), 1169-1174. https://doi.org/10.1002/adhm.201400797

Document status and date:

Published: 03/06/2015

DOI:

10.1002/adhm.201400797

Document Version:

Publisher's PDF, also known as Version of record

Document license:

Taverne

Please check the document version of this publication:

- A submitted manuscript is the version of the article upon submission and before peer-review. There can be important differences between the submitted version and the official published version of record.

People interested in the research are advised to contact the author for the final version of the publication, or visit the DOI to the publisher's website.

- The final author version and the galley proof are versions of the publication after peer review.

- The final published version features the final layout of the paper including the volume, issue and page numbers.

Link to publication

\footnotetext{
General rights rights.

- You may freely distribute the URL identifying the publication in the public portal. please follow below link for the End User Agreement:

www.umlib.nl/taverne-license

Take down policy

If you believe that this document breaches copyright please contact us at:

repository@maastrichtuniversity.nl

providing details and we will investigate your claim.
}

Copyright and moral rights for the publications made accessible in the public portal are retained by the authors and/or other copyright owners and it is a condition of accessing publications that users recognise and abide by the legal requirements associated with these

- Users may download and print one copy of any publication from the public portal for the purpose of private study or research.

- You may not further distribute the material or use it for any profit-making activity or commercial gain

If the publication is distributed under the terms of Article 25fa of the Dutch Copyright Act, indicated by the "Taverne" license above, 


\title{
Creeping Proteins in Microporous Structures: Polymer Brush-Assisted Fabrication of 3D Gradients for Tissue Engineering
}

\author{
Michel Klein Gunnewiek, Andrea Di Luca, Hermannes Z. Bollemaat, \\ Clemens A. van Blitterswijk, G. Julius Vancso, Lorenzo Moroni,* \\ and Edmondo M. Benetti*
}

Recent research in tissue engineering and regenerative medicine is increasingly revolving around effective fabrication techniques to create functional scaffolds for cell manipulations. Specifically, 3D supports presenting temporal and spatial control over the exposure of protein cues are desirable as they would allow spatial control over cell behavior. ${ }^{[1,2]}$ To achieve this objective, a number of methods have been proposed to create synthetic extracellular matrices (ECMs) with gradient-like chemical compositions, thus mimicking the continuous variation characteristic of natural ECM.

The production of biomolecular gradients on 2D supports was proven as an effective approach to spatially adjust cell adhesion, migration, and proliferation on planar substrates. ${ }^{[3-7]}$ Following the development of increasingly sophisticated 3D synthetic ECMs, diverse methodologies for the fabrication of protein gradients in 3D environments have also been proposed. These biomaterials are obtained by employing hydrogelsupports $^{[8-11]}$ and electrospun fibers ${ }^{[12,13]}$ but they commonly require complicated multisteps preparations without achieving spatial control of the biomolecules.

The simple exposure of 3D supports to different protein solutions with variable composition ${ }^{[14,15]}$ consented the production

M. Klein Gunnewiek, H. Z. Bollemaat, Prof. G. J. Vancso, Dr. E. M. Benetti

Department of Materials Science and Technology of Polymers, MESA+ Institute for Nanotechnology

University of Twente, P.O. Box 217

7500 AE, Enschede, The Netherlands

E-mail: edmondo.benetti@mat.ethz.ch

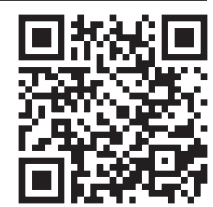

A. Di Luca, Prof. C. A. van Blitterswijk, Dr. L. Moroni

Department of Tissue Regeneration

MIRA Institute for Biomedical Technology and Technical Medicine

University of Twente, P.O. Box 217

7500 AE, Enschede, The Netherlands

E-mail: I.moroni@utwente.nl

Prof. C. A. van Blitterswijk, Dr. L. Moroni

Department of Complex Tissue Regeneration

MERLN Institute for Technology Inspired Regenerative Medicine

Maastricht University, P.O. Box 616

6200 MD, Maastricht, The Netherlands

Dr. E. M. Benetti

Laboratory for Surface Science and Technology (LSST)

Department of Materials, ETH Zürich

Vladimir-Prelog-Weg 5, CH-8093 Zürich, Switzerland

DOI: 10.1002/adhm.201400797 of biomaterials showing a continuous variation of protein coverage, yet just along one main scaffold axis. Following such preparations, electrospun fibers with varying composition could be deposited on a movable stage while changing feed, in order to create (bio)chemical gradients along the horizontal or the vertical direction.

Protein gradients were alternatively fabricated within photocrosslinked hydrogels by gradually or locally exposing different parts of the matrix to light, ${ }^{[8,9]}$ followed by bioconjugation. Analogous monoaxial hydrogel-supported gradients were also successfully produced by electrochemically controlled enzymatic polymerization. ${ }^{[16]}$

Higher control over the compositional changes characterizing synthetic ECMs was accomplished via lay)er-by-layer ${ }^{[10]}$ or "gradient maker"-assisted ${ }^{[17-19]}$ fabrications. In these processes, hydrogels presenting gradient compositions along their deposition/building direction were formed. ${ }^{[10,20]}$

The above-mentioned methods, yielding gradient compositions, necessitated multiple processing steps and/or timeconsuming chemical treatments. These drawbacks would render them unsuitable for clinical use, where fast and lowcost manipulations to reproduce and directly apply scaffolds on patients are needed. In addition, these techniques supported the formation of mono- or bidirectional gradients, while the development of concentration changes in 3D still remained a challenge.

Synthetic supports which mimicked the multiaxial compositional gradients, characteristic of natural ECM in vivo, would be needed to reproduce the compositional diversity of tissue environments within simplified and easily accessible matrices. These supports could be applied not only as scaffolds for the regeneration of complex tissues, but also as $3 \mathrm{D}$ architectures for studying cells and bacteria adhesion and migration ${ }^{[9,12,16]}$ in 3D environments.

Triggered by this challenge, we introduce here a novel fabrication strategy which features a practical and affordable construction of 3D ECMs displaying multidirectional variations of (bio)chemical environments. Specifically, we coupled rapid prototyping $(\mathrm{RP})^{[21-23]}$ to surface modification strategies based on surface-initiated polymerizations $(\mathrm{SIP})^{[24,25]}$ in order to fabricate microporous and highly functional 3D architectures which could be subsequently locally decorated with different types of biomolecules. In this process, poly( $\varepsilon$-caprolactone) (PCL) scaffolds characterized by a regularly layered network of microfibers 


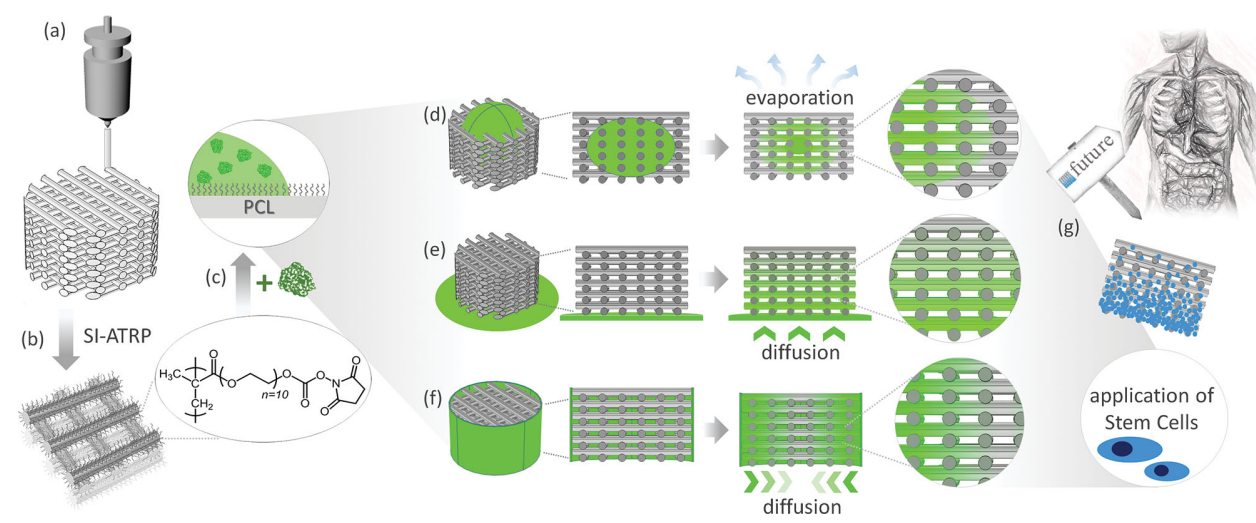

Scheme 1. POEGMA-brush-assisted fabrication of 3D protein gradients within PCL scaffolds and application as platforms for stem cells immobilization. a) Fabrication of PCL microporous scaffolds by rapid prototyping; b) SI-ATRP of OEGMA from the PCL fibers network and subsequent activation of hydroxyl side chains to form NHS esters; c) conjugation of proteins at the brush interface by controlled diffusion of solutions within the 3D scaffolds. This last step is especially highlighted in $(d-f)$. d) Incorporation of microdroplets of protein solutions and subsequent solvent evaporation generated radial concentration gradients on brushes. e) Controlled diffusion from a soaked paper reservoir allowed the formation of axial protein concentration gradients. f) Wrapped reservoirs enabled protein diffusion from the lateral walls of the scaffolds and the consequent fabrication of radial protein gradient developing oppositely to (d). g) The protein-functionalized scaffolds were finally applied for the spatially controlled immobilization of hMSCs.

(Scheme 1a) were modified by surface-initiated atom transfer radical polymerization (SI-ATRP) of poly[oligo (ethylene glycol) methacrylate] (POEGMA) (Scheme 1b). The so-formed, sub-100 nm POEGMA brushes uniformly covered the scaffold surface and allowed protein coupling at the exposed hydroxyl functions of the grafted polymer ${ }^{[26,27]}$ (Scheme 1c). In addition, the biopassive character of POEGMA brushes ${ }^{[28-30]}$ assured robust covalent linkage of cues avoiding any further unspecific contamination of the matrix by physisorption of other biomolecules or bacteria attachment. The formation of protein gradients by surface conjugation was accomplished exploiting the physico-chemical properties of the hydrophilic brush in combination with the microporous structure of the PCL scaffolds. Uniform coverage of PCL by hydrophilic POEGMA brush caused a marked increase in wettability of the support (water contact angle (CA) varied from $73^{\circ}$ to $45 \pm 3^{\circ}$, as shown in Table S1, Supporting Information). This phenomenon reflected a substantial increase of surface energy within the 3D scaffolds. ${ }^{[31,32]}$ Hence, the interplay between high surface energy-driven wetting by the POEGMA brush and capillary forces within the microporous supports promoted the diffusion of aqueous solutions into the matrix (as highlighted in Scheme 1d and in the light microscope images shown in Figure S1, Supporting Information). We exploited this simple process to incorporate protein solutions into the scaffolds and consequently couple proteins at the pre-activated brush (via NHS chemistry ${ }^{[33]}$ as described in the Experimental Section). Diffusion of protein solution microdroplets (Scheme 1d) and subsequent concentration of the solutions toward the inner core of the structure finally induced a radial variation of protein surface concentration (Figure 1a-c). Alternatively, protein solutions could be made to diffuse from soaked paper sheets used as solution reservoir put into close contact with the scaffolds (Scheme 1e and Figure 1d-f). In both cases, simple process parameters like microdroplets volume and diffusion time from external reservoirs allowed spatial 3D control over the concentration of the coupled proteins (Figures S2 and S3, Supporting Information).
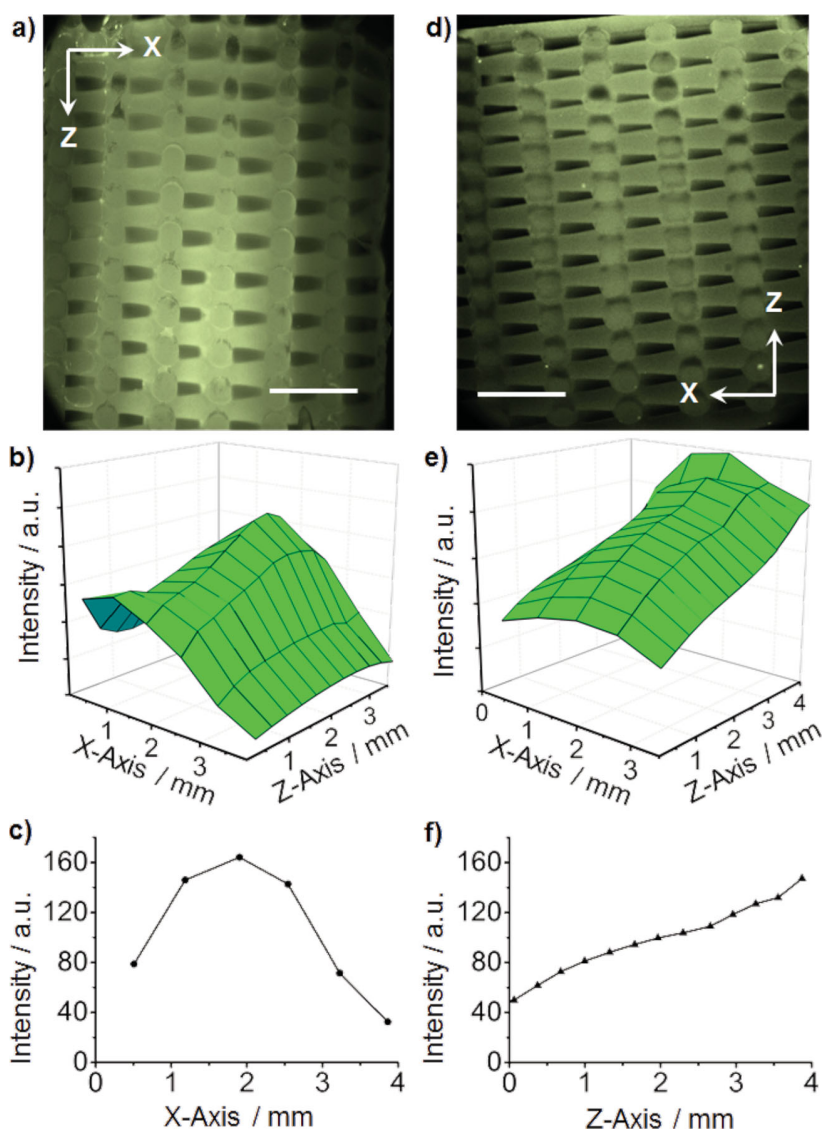

Figure 1. Radial and axial 3D gradients of proteins within POEGMA brush-coated microporous scaffolds. a,d) Fluorescent images and $b, e)$ the corresponding 3D intensity profile of the vertical cross-section of PCL-POEGMA scaffolds functionalized with $a-c)$ a radial and $d-f$ ) an axial gradient of BSA-FITC concentration. Intensity profiles along the c) $x$-axis and the $f$ ) $z$-axis of the radial and the axial $3 D$ gradient, respectively. 
Figure 1a-c show radial 3D gradients of fluorescently labeled bovine serum albumin (BSA) attached to PCL-POEGMA scaffolds by incorporation of protein solution microdroplets and subsequent bioconjugation. Having calculated through Equation (1) the inner volume of each scaffold as $25 \mu \mathrm{L}$, we applied different volumes of microdroplets in order to prepare radial gradients, yielding gradient protein coverages. Fluorescent microscopy of the cross-sectioned 3D structures revealed the protein surface concentration profiles within the scaffolds. As shown in Figure S2a,b, Supporting Information, gradient formation from $2 \mu \mathrm{L}$ protein solutions produced a radial gradient with a high concentration of proteins in the inner core and a steady decrease of coverage after around $250 \mu \mathrm{m}$ from the center of the scaffolds. Increase of the microdroplet volume to $10 \mu \mathrm{L}$ produced a more uniform protein coverage through the supports with just the outer walls remaining unfunctionalized (Figure 1a-c). Although the volume used for these depositions was less than half of the total inner volume of the 3D scaffolds, fast diffusion of protein solutions along the hydrophilic brushcoated fibers most likely smoothened the profile of the protein gradient across the 3D structures.

Brush-supported protein gradients developing axially along the 3D scaffold (from one external side toward the center) were obtained by applying a porous paper sheet as solution reservoir and allowing the protein medium to diffuse by capillary forces (Scheme 1e, Figure 1d-f, and Figure S3, Supporting Information). Slow wetting of brush-coated fibers enabled the adjustment of the protein gradient profile as a function of the diffusion time (and thus bioconjugation time at the POEGMA brush surface).

The fluorescent images in Figure S3, Supporting Information, showed different axial gradient profiles obtained by varying the diffusion/bioconjugation time. Both $3 \mathrm{D}$ and the $2 \mathrm{D}$ intensity plots reconstructed from the fluorescence images showed that, after $30 \mathrm{~min}$ of diffusion, proteins were mainly immobilized within $700 \mu \mathrm{m}$ from the base of the scaffold (Figure S3a,b, Supporting Information). Following longer diffusion time, protein solutions covered larger volumes inside the scaffolds, homogenizing the protein coverage. After $60 \mathrm{~min}$ of diffusion (Figure S3c,d, Supporting Information), proteins covered almost $1 / 3$ of the distance across the scaffold main axis ( $Z$ axis in Figure S3g, Supporting Information), keeping a rather uniform surface concentration along the $X$-axis (Figure S4, Supporting Information). After $120 \mathrm{~min}$ of diffusion, the protein solutions completely wetted the inner structure of the scaffolds and consequently created a nearly linear gradient of protein coverage on the fibers (Figure $1 \mathrm{~d}-\mathrm{f}$ ).

The procedures used for the fabrication of single protein gradients were combined to produce double gradients of different protein species. After the formation of either a radial or an axial 3D distribution of proteins the scaffolds were not entirely covered by protein solutions. Consequently, unfunctionalized POEGMA brushes were still available for bioconjugation on the unwetted areas within the 3D structure. Hence, a second protein solution could be additionally applied to produce a surface concentration gradient which developed in the opposite direction to the pre-existing one (as schematized in Scheme 1d-f). These "double" protein distributions are referred to as 3D radial and axial double gradients. In order to ease their analysis by fluorescent microscopy, we applied two solutions of differently labeled BSA (FITC and Texas Red, named as protein A and B, respectively) as representative of two different protein species. As shown in Figure $2 \mathrm{a}-\mathrm{d}$, a $3 \mathrm{D}$ radial double gradient of two different proteins was produced first incorporating a microdroplet of protein A solution within the POEGMA-PCL scaffold and subsequently wrapping around its outer surface a paper reservoir soaked with protein $\mathrm{B}$. Alternatively, in order to fabricate a 3D axial double gradient of protein $\mathrm{A}$ and $\mathrm{B}$, two different protein media were allowed to diffuse from two reservoirs placed in contact with each opposite "face" of the scaffold (Figure 2e-h).

As shown in Figure 2a,c and in the corresponding 3D intensity reconstructions from a typical functionalized scaffold, radial double gradients displayed continuous and interconnected variations of concentrations of proteins $\mathrm{A}$ and $\mathrm{B}$. The radial double gradients typically presented a high concentration of protein A in the core of the scaffold, which decreased beyond around $1.5 \mathrm{~mm}$ toward the outer part of the scaffold
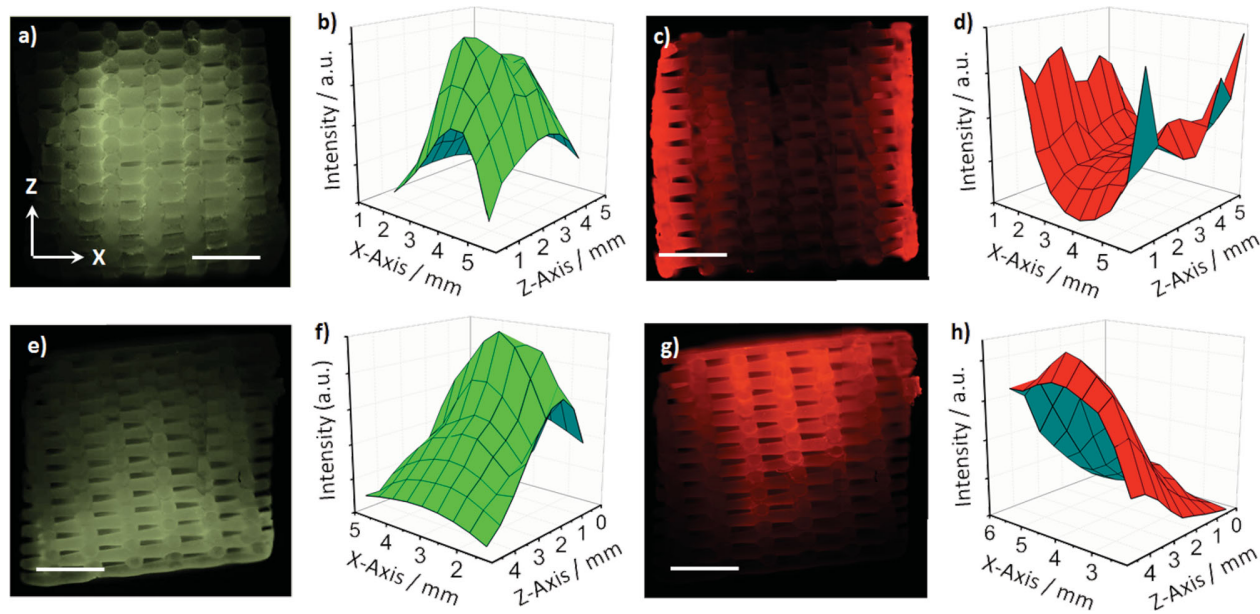

Figure 2. Double 3D gradients of proteins within POEGMA brush-coated microporous scaffolds. a,c,e,g) Fluorescent images and b,d,f,h) the corresponding intensity plots of PCL-POEGMA scaffolds functionalized with BSA. Double gradients in BSA concentrations were fabricated both in the radial and axial directions; a,b) inside-to-outside and c,d) outside-to-inside; e,f) bottom-to-top and g,h) top-to-bottom. Scale bar is $1 \mathrm{~mm}$. 
(Figure 2b). Protein B concentrations, on the contrary, developed from the outer walls of the scaffold and showed high surface concentration within around $1 \mathrm{~mm}$ toward the interior of the support (Figure 2d).

Axial double gradients (Figure 2e-g) showed a uniform and interconnected variation of the two proteins concentration across the main scaffold axis (Z-axis in Figure 2f,h). In these cases, a well-pronounced concentration distribution of the two protein species along opposite directions was clearly showed.

To prove the applicability of the proposed fabrications for cell manipulations, we reproduced both radial and axial 3D gradients using fibronectin (FN) as a biological cue known to promote cell adhesion. Also in this case, brush coatings based on NHS-activated POEGMA were used as platforms for bioconjugation and the successful linkage of FN was subsequently proved by X-ray photoelectron spectroscopy (XPS, Figure S5, Supporting Information). The maximum surface coverage of FN obtained was estimated by uniformly immersing a NHSPOEGMA-coated PCL film in the same FN solution used for the gradient deposition. The incubation time was set as the maximum contact time of the FN solution drop within the NHSPOEGMA-coated 3D scaffold during the gradient deposition by diffusion (before rinsing step). XPS was used to estimate the maximum surface coverage of FN on POEGMA brush, which corresponded to the highest protein concentration across the $3 \mathrm{D}$ gradients. This has been calculated as $40 \pm 5 \mathrm{ng} \mathrm{cm}^{-2}$, from which value FN concentration progressively decayed according to the $3 \mathrm{D}$ gradient.

Following the controlled diffusion of FN solutions, functionalized scaffolds presenting a radial and an axial concentration gradient were subsequently incubated with hMSCs during one day. The adhered cells were subsequently stained using methylene blue and the scaffolds were sectioned along the appropriate axis in order to visualize their interior.

$3 \mathrm{D}$ scaffolds presenting a radial gradient of $\mathrm{FN}$ from the core to the outer volume of the scaffolds showed a higher number of cells in the interior of the structure, while at its periphery only few cells could be visualized (Figure 3a,b). In a similar way, axial gradients of brush-supported FN induced hMSCs adhesion mainly on one side of the scaffold, according to FN distribution and following the gradient morphology (Figure 3c). Scaffolds completely functionalized with FN and "bare" POEGMA-coated supports were also seeded with hMSCs and were used as controls (Figure 3d,e). As shown in Figure 3d, the cells completely covered the uniformly functionalized scaffolds without showing any preferred area to settle. In comparison, brush-coated scaffold without FN showed no cells due to the biopassive nature of unfunctionalized POEGMA (Figure 3e). To investigate the viability of hMSCs adhering onto the POEGMA-FN-coated 3D scaffolds, high magnification scanning electron microscopy (SEM) images were taken (Figure S6, Supporting Information). The clear deposition of ECM (Figure S6b-f, Supporting Information) and the highly spread appearance of the cells (Figure S6f, Supporting Information) confirmed their viability.

All these results confirmed that the fabrication method proposed in this work represents a highly efficient strategy not only to create $3 \mathrm{D}$ protein gradients with designed morphologies, but also to control spatially cell adhesion within 3D scaffolds.

The use of hydrophilic and highly functional brush layers coupled to a structured support with controlled microporosity triggered diffusion and concomitant covalent immobilization of proteins from solutions. These processes could be easily manipulated by varying parameters as solution volumes and diffusion time within the 3D structures. This enabled the fabrication of $3 \mathrm{D}$ axial and radial protein gradients with tailored morphologies.

PCL-POEGMA scaffolds with 3D protein gradients also have the potential to be easily reproduced in clinics since they do not require any inert environment or complicated chemistry. Brush-coated scaffolds could be simply incubated with the required proteins and directly applied to patients in or without the presence of cell preparations. In this context, the versatility of this technique would support the combination of multiple cues $^{[34-38]}$ that could eventually trigger cell adhesion, migration, or differentiation, in a single $3 \mathrm{D}$ porous structure. All the above-mentioned features make the method presented here a practical and affordable strategy to synthetically mimic natural ECMs and their 3D multidirectional diversity.

\section{Experimental Section}

Materials: Oligo(ethylene glycol) methacrylate (OEGMA, Aldrich, $\mathrm{Mn}=526 \mathrm{~g} \mathrm{~mol}^{-1}$ ) was purified from hydrochinone inhibitors by passing it through a basic alumina column using dichloromethane
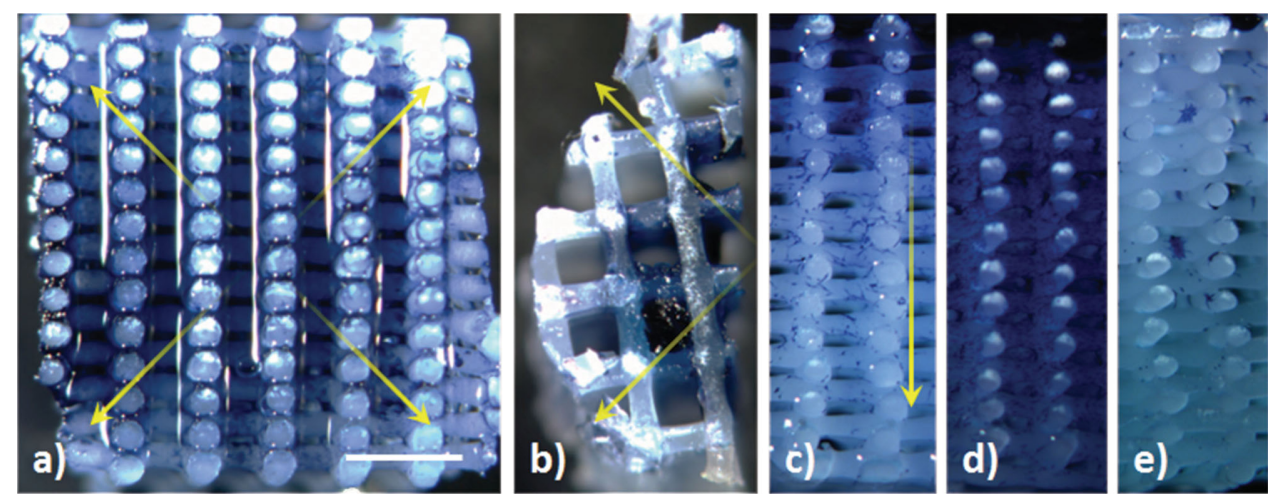

Figure 3. Optical images of methylene blue stained hMSCs adhering on PCL-POEGMA scaffolds. Radial gradient in FN concentration showing the a) vertical and b) horizontal cross-section; c) an axial gradient in FN concentration, d) a POEGMA coating fully covered by FN, and e) a bare POEGMA coating. The yellow arrows indicate the direction of decreasing FN concentration. Scale bar is $1 \mathrm{~mm}$. 
(DCM, Biosolve) as eluent. Afterward, DCM was removed under vacuum. Copper(I) chloride ( $\mathrm{CuCl}$, Aldrich, 98\%) was purified by stirring in glacial acetic acid, filtering, and washing with ethanol three times, followed by drying in vacuum at room temperature overnight. $\mathrm{PCL}(\mathrm{Mn}=45 \mathrm{kDa})$ was obtained from Sigma. Copper(II) bromide (Sigma-Aldrich, $\geq 99 \%$ ), methanol (Biosolve, absolute), isopropanol (iPA, Biosolve), ethylenediamine (EDA, Sigma-Aldrich, $\geq 99 \%$ ), dry hexane (Acros, Extra Dry over Molecular Sieve, 97\%), $\mathrm{N}, \mathrm{N}$-dimethylformamide (DMF, Acros, extra dry over molecular sieve, $99,8 \%$ ), pyridine (Sigma-Aldrich, anhydrous, 99,8\%), 2,2'-bipyridil (BiPy, Sigma-Aldrich, $\geq 99 \%$ ), 2-bromoisobutyryl xbromide (BIBB, Aldrich, 98\%), ethylenediaminetetraacetic acid disodium salt dihydrate (EDTA, Sigma, 99\%), 4-dimethylaminopyridine (DMAP, Sigma-Aldrich, $\geq 99 \%$ ), N, N'-disuccinimidyl carbonate (DSC, Sigma-Aldrich, 98\%), phosphate buffered saline (PBS) (Invitrogen), and triethylamine (SigmaAldrich, $\geq 99 \%$ ) were used as received. For brush surface modification, fluorescein-labeled BSA, Texas Red-labeled BSA, and FN were used as obtained from Invitrogen and diluted to the appropriate concentration. All water used in the experiments was Millipore Milli-Q grade. Colonypicked human mesenchymal stem cells hMSCs (male, age 22) were retrieved from the Institute of Regenerative Medicine (Temple, Texas). For cell culture, basic cell culture media was prepared by adding to a $\alpha$-MEM cell medium (Invitrogen) $10 \mathrm{v} / \mathrm{v} \%$ of fetal bovine serum (FBS), $2 \times 10^{-3} \mathrm{M}$ of L-glutamine, $100 \mathrm{U} \mathrm{mL}$ - of penicillin, $100 \mu \mathrm{g} \mathrm{mL} \mathrm{L}^{-1}$ of streptomycin, and $0.2 \times 10^{-3} \mathrm{M}$ of ascorbic acid. All these components were obtained from Invitrogen.

Scaffold Fabrication: 3D microporous PCL scaffolds were fabricated using a rapid prototyping technique (SysENG $\mathrm{GmbH}$, Germany). The PCL granulate was loaded into a metal syringe wrapped with a heating jacket. The copolymer was heated to $100^{\circ} \mathrm{C}$ for about $45 \mathrm{~min}$ until it had reached the molten phase and could be dispensed through the extruder. A nitrogen pressure of 5 bars was applied on top of the metal cartridge to facilitate polymer strand extrusion from a Luer Lock stainless steel needle. A rectangle block model of $4 \mathrm{~mm}$ in height and $20 \times 20 \mathrm{~mm}$ in area was plotted layer-by-layer and the architecture (0-90) was controlled by the Bioplotter CAD/CAM software. The layered fibers within the scaffolds were assembled in a woodpile structure having the following characteristic parameters: diameter $\left(d_{1}\right)=250 \mu \mathrm{m}$, spacing $\left(d_{2}\right)=650 \mu \mathrm{m}$, layer thickness $\left(d_{3}\right)=150 \mu \mathrm{m}$. From these values, the theoretical porosity $(\approx 50 \%)$ of the scaffold was calculated, according to

$$
P=1-\frac{V_{\text {scaffold }}}{V_{\text {cube }}}=1-\frac{\pi}{4} \times \frac{d_{1}^{2}}{d_{2} \times d_{3}}
$$

The 3D scaffolds used for the fabrication of the brush-supported protein gradients were cut from the rectangle block in order to obtain cylindrical shapes with a height and a diameter of $4 \mathrm{~mm}$.

Activation of the Polymer Films: 3D scaffolds were activated through immersion in a $5 \times 10^{-3} \mathrm{M}$ isopropanol solution of EDA. The reaction was allowed to proceed for $10 \mathrm{~min}$ at room temperature. Scaffolds were then rinsed with ice-cold water and finally dried in a stream of nitrogen. The aminated PCL scaffolds were immersed into $20 \mathrm{~mL}$ of dry hexane and $20 \mu \mathrm{L}$ of dry pyridine, to which $20 \mu \mathrm{L}$ of BIBB was added dropwise. The reaction mixture was gently stirred for $1 \mathrm{~h}$ at room temperature to produce the 2-bromoisobutyrate- $\mathrm{PCL}$ surface $(\mathrm{PCL}-\mathrm{Br})$. $\mathrm{PCL}-\mathrm{Br}$ scaffolds were later on washed repeatedly with an ethanol/water $(1 / 1$, $\mathrm{v} / \mathrm{v}$ ) mixture and finally dried under a stream of nitrogen.

Atom Transfer Radical Polymerization of OEGMA: Purified OEGMA monomer $(5 \mathrm{~g}, 9.5 \mathrm{mmol}$ ) and 2,2'bipyridine $(81.7 \mathrm{mg}, 0.52 \mathrm{mmol})$ were added to a water $(5 \mathrm{~mL})$ and methanol $(1.26 \mathrm{~mL})$ mixture. The solution was purged with argon for $30 \mathrm{~min}$. CuCl (18.75 $\mathrm{mg}, 0.19 \mathrm{mmol})$ and $\mathrm{CuBr}_{2}(2 \mathrm{mg}, 0.009 \mathrm{mmol})$ were added into another reaction flask and also flushed with argon. Monomer, ligand, and catalyst were then combined and stirred for other $30 \mathrm{~min}$ to facilitate the formation of the organometallic complex. This solution was then transferred into the flasks containing PCL-Br substrates. The flasks were sealed with rubber septa and kept at room temperature under nitrogen. Following
$10 \mathrm{~min}$ of reaction time the substrates were removed from the polymerization solution, exhaustively rinsed with water to remove any unreacted compound, and finally dried under a stream of nitrogen. From detailed kinetics studies of SI-ATRP from PCL substrates (Supporting Information) the average thickness of POEGMA brushes following $10 \mathrm{~min}$ of polymerization resulted as $15 \mathrm{~nm}$ (Figure S7, Supporting Information). Before any further manipulation, PCL-POEGMA scaffolds were incubated in a $0.1 \mathrm{~m}$ aqueous EDTA solution overnight to remove any copper trace. In order to test the successful uniform grafting of POEGMA, functionalized scaffolds were finally placed in water containing vials (Figure S8, Supporting Information). Pure PCL scaffolds floated due to their hydrophobic nature, while PCL-POEGMA scaffolds sank to the bottom of the vials.

Functionalization of PCL-POEGMA Scaffolds: POEGMA brushes on PCL scaffolds were activated by placing them in a dry DMSO solution containing $200 \times 10^{-3} \mathrm{M}$ of DSC and DMAP. Later on, the samples were incubated in a protein solution containing either $0.4 \times 10^{-6} \mathrm{M}$ fluorescently labeled BSA or $0.1 \times 10^{-6} \mathrm{M} \mathrm{FN}$. To fabricate a radial gradient in protein concentration from the core to the outer surface of the $3 \mathrm{D}$ scaffolds, microdroplets of either 2 or $10 \mu \mathrm{L}$ of PBS protein solutions were placed on the scaffold and let diffuse inside their core. After 10 $\mathrm{min}$ the scaffolds were extensively rinsed with milli-Q water, blow-dried with a stream of $\mathrm{N}_{2}$, cut over their mid-section, and finally imaged with a fluorescent microscope. Reversed radial gradients from the outer surface of the scaffolds to the core were fabricated using microporous paper sheets soaked in PBS protein solutions as reservoirs. Soaked paper sheets were wrapped around the scaffolds and kept into close contact in order to let the protein solutions diffuse within the scaffolds interior. Following $3 \mathrm{~min}$ of incubation the scaffolds were extensively rinsed with milli-Q water, blow-dried with a stream of $\mathrm{N}_{2}$, cut over their mid-section, and finally imaged with a fluorescent microscope. Protein gradients along the axial direction of the scaffolds were fabricated by placing the DSC-activated PCL-POEGMA scaffolds on top of a microporous paper sheet previously soaked with protein solutions. The contact between the scaffold's outer surface and the paper reservoir was assured by placing a weight of $7.5 \mathrm{~g}$ on top of the scaffolds. Following different diffusion times $(30,60$, and $120 \mathrm{~min})$ the scaffolds were extensively rinsed with milli-Q water, blow-dried with a stream of $\mathrm{N}_{2}$, cut over their mid-section, and finally imaged with a fluorescent microscope.

Fluorescent Microscopy: Fluorescent images of the scaffolds functionalized with labeled BSA species were recorded using a Nikon Eclipse E600. Fluorescein-labeled BSA was visualized using a filter with an excitation and emission wavelength of 475 and $530 \mathrm{~nm}$, respectively. For Texas Red-labeled BSA, a filter with an excitation and emission wavelength of 559 and $630 \mathrm{~nm}$, respectively, was used. Unmodified PCL scaffolds were used to set the exposure time and the gain values, such that the autofluorescence of the bare polymer was suppressed. Fluorescent pictures were taken from the vertical cross-section by cutting the scaffolds through the center along the $z$-axis. An assumption is made that the functionalization of the POEGMA layer is homogeneous and that the scaffold can be turned freely around the $z$-axis.

Cell Culture and Cell Staining: hMSCs were cultured at $37{ }^{\circ} \mathrm{C}$ in a humidified atmosphere of $5 \%$ carbon dioxide, using as culture medium $\alpha$-MEM supplemented with $10 \mathrm{v} / \mathrm{v} \%$ FBS, $2 \times 10^{-3} \mathrm{M}$ L-glutamine, $0.2 \times 10^{-3} \mathrm{M}$ L-ascorbic acid 2-phosphate magnesium salt, $100 \mathrm{U} \mathrm{\textrm {mL } ^ { - 1 }}$ of penicillin, and $10 \mu \mathrm{g} \mathrm{mL}^{-1}$ of streptomycin. The cells were seeded at a density of 500000 cells in $40 \mu \mathrm{L}$ per scaffold and after $4 \mathrm{~h}$, cell culture media was added. The scaffolds were kept in an incubator for one day. After the required culturing time, the cells were fixed with a $3.7 \mathrm{v} / \mathrm{v} \%$ formaldehyde solution in PBS. Subsequently, the cells were stained using a $1 \%$ methylene blue solution in water and visualized using an optical microscope.

\section{Supporting Information}

Supporting Information is available from the Wiley Online Library or from the author. 


\section{Acknowledgements}

M.K.G. and A.D.L. contributed equally to this work. This work was financially supported by the MESA+ Institute for Nanotechnology of the University of Twente, by the Technology foundation STW (STW, 11135), and by the Swiss National Foundation (SNSF "Ambizione" PZ00P2148156). Some of the materials employed in this work were provided by the Texas A\&M Health Science Center College of Medicine Institute for Regenerative Medicine at Scott \& White through a grant from NCRR of the NIH (Grant No. P40RR017447). The authors thank Prof. Lucio Isa $(\mathrm{ETHz})$ and Dr. Mark Hempenius (UTwente) for the many useful discussions.

Received: December 15, 2014 Revised: January 22, 2015 Published online: February 13, 2015

[1] M. P. Lutolf, J. A. Hubbell, Nat. Biotechnol. 2005, 23, 47.

[2] J. Genzer, Annu. Rev. Mater. Res. 2012, 42, 435.

[3] S. T. Plummer, Q. Wang, P. W. Bohn, R. Stockton, M. A. Schwartz, Langmuir 2003, 19, 7528.

[4] R. R. Bhat, B. N. Chaney, J. Rowley, A. Liebmann-Vinson, J. Genzer, Adv. Mater. 2005, 17, 2802.

[5] R. R. Bhat, M. R. Tomlinson, J. Genzer, J. Polym. Sci., Part B: Polym. Phys. 2005, 43, 3384.

[6] L. Li, J. Wu, C. Gao, Colloids Surf. B 2011, 85, 12.

[7] J. A. Burdick, A. Khademhosseini, R. Langer, Langmuir 2004, 20 , 5153.

[8] B. D. Polizzotti, B. D. Fairbanks, K. S. Anseth, Biomacromolecules 2008, 9, 1084

[9] R. G. Wylie, S. Ahsan, Y. Aizawa, K. L. Maxwell, C. M. Morshead, M. S. Shoichet, Nat. Mater. 2011, 10, 799.

[10] A. Sala, P. Hanseler, A. Ranga, M. P. Lutolf, J. Vörös, M. Ehrbar, F. E. Weber, Integr. Biol. 2011, 3, 1102.

[11] K. A. Mosiewicz, L. Kolb, A. J. van der Vlies, M. M. Martino, P. S. Lienemann, J. A. Hubbell, M. Ehrbar, M. P. Lutolf, Nat. Mater. 2013, 12, 1072.

[12] J. Shi, L. Wang, F. Zhang, H. Li, L. Lei, L. Liu, Y. Chen, ACS Appl. Mater. Interfaces 2010, 2, 1025.

[13] B. Zou, Y. Liu, X. Luo, F. Chen, X. Guo, X. Li, Acta Biomater. 2012, $8,1576$.
[14] Handarmin, G. Tan, B. Sundaray, G. Marcy, E. Goh, S. Chew, Drug Delivery Transl. Res. 2011, 1, 147.

[15] X. Zhang, X. Gao, L. Jiang, J. Qin, Langmuir 2012, 28, 10026.

[16] V. Milleret, B. R. Simona, P. S. Lienemann, J. Vörös, M. Ehrbar, Adv. Healthcare Mater. 2014, 3, 508.

[17] S. A. DeLong, A. S. Gobin, J. L. West, J. Controlled Release 2005, 109, 139.

[18] S. A. DeLong, J. J. Moon, J. L. West, Biomaterials 2005, 26, 3227.

[19] D. Guarnieri, A. De Capua, M. Ventre, A. Borzacchiello, C. Pedone, D. Marasco, M. Ruvo, P. A. Netti, Acta Biomater. 2010, 6, 2532.

[20] X. Wang, E. Wenk, X. Zhang, L. Meinel, G. Vunjak-Novakovic, D. L. Kaplan, J. Controlled Release 2009, 134, 81.

[21] D. W. Hutmacher, J. Biomater. Sci., Polym. Ed. 2001, 12, 107.

[22] S. F. Yang, K. F. Leong, Z. H. Du, C. K. Chua, Tissue Eng. 2002, 8, 1.

[23] W.-Y. Yeong, C.-K. Chua, K.-F. Leong, M. Chandrasekaran, Trends Biotechnol. 2004, 22, 643.

[24] S. Edmondson, V. L. Osborne, W. T. S. Huck, Chem. Soc. Rev. 2004, $33,14$.

[25] R. Barbey, L. Lavanant, D. Paripovic, N. Schuwer, C. Sugnaux, S. Tugulu, H. A. Klok, Chem. Rev. 2009, $109,5437$.

[26] S. Tugulu, A. Arnold, I. Sielaff, K. Johnsson, H.-A. Klok, Biomacromolecules 2005, 6, 1602.

[27] S. Tugulu, P. Silacci, N. Stergiopulos, H.-A. Klok, Biomaterials 2007, $28,2536$.

[28] H. Ma, J. Hyun, Z. Zhang, T. P. Beebe, A. Chilkoti, Adv. Funct. Mater. 2005, 15, 529.

[29] J. E. Raynor, T. A. Petrie, A. J. García, D. M. Collard, Adv. Mater. 2007, 19, 1724

[30] L. Moroni, M. Klein Gunnewiek, E. M. Benetti, Acta Biomater. 2014, 10, 2367.

[31] M. Kobayashi, Y. Terayama, H. Yamaguchi, M. Terada, D. Murakami, K. Ishihara, A. Takahara, Langmuir 2012, 28, 7212.

[32] G. Marletta, G. Ciapetti, C. Satriano, F. Perut, M. Salerno, N. Baldini, Biomaterials 2007, 28, 1132.

[33] S. Diamanti, S. Arifuzzaman, A. Elsen, J. Genzer, R. A. Vaia, Polymer 2008, 49, 3770

[34] E. N. Chiang, R. Dong, C. K. Ober, B. A. Baird, Langmuir 2011, 27, 7016.

[35] M. Navarro, E. M. Benetti, S. Zapotoczny, J. A. Planell, G. J. Vancso, Langmuir 2008, 24, 10996.

[36] S. Yuan, G. Xiong, X. Wang, S. Zhang, C. Choong, J. Mater. Chem. 2012, 22, 13039.

[37] S. Yuan, G. Xiong, A. Roguin, C. Choong, Biointerphases 2012, 7, 30.

[38] T. Ren, Z. Mao, J. Guo, C. Gao, Langmuir 2013, $29,6386$. 